\title{
LA PRESENCIA AFRICANA EN LA INMIGRACIÓN ESPAÑOLA DEL CAMBIO DE SIGLO
}

\author{
POR \\ JUAN A. CEBRIÁN, MARÍA ISABEL BODEGA \\ Y ANA M. LÓPEZ-SALA
}

Introducción

Hace ya siete años (Bodega, I., Cebrián, J. A. y otros, 1993), publicamos un artículo sobre la reciente inmigración de norteafricanos a España. En aquel momento, la inmigración laboral española se encontraba en un estado germinal. Por ello, no existía una legislación apropiada para incorporarla satisfactoriamente. De hecho, el artículo a que nos referimos se dedicó al estudio de las consecuencias sociales del decreto de regularización - legislación $a d$ hoc — de población extranjera más importante hasta ese momento (1991). En las conclusiones de aquel trabajo formulamos tres preguntas, que este artículo intenta contestar: ¿seguirá creciendo al mismo ritmo la población laboral extranjera? ¿se asentarán los inmigrantes laborales? ¿existen mecanismos eficaces de control de las migraciones laborales hacia España?

Este artículo se estructura en cuatro epígrafes. En el primero, nos dedicamos a actualizar la información sobre la situación económico demográfica de las dos riberas (Norte y Sur) del Mediterráneo. Nuestro análisis confirma que en la última década del siglo xx se ha llegado a un cierto equilibrio demográfico, al reducirse las tasas de crecimiento de

Juan A. Cebrián y María Isabel Bodega: Instituto de Economía y Geografía, CSIC.

Ana M. López-Sala: Instituto de Filosofía, CSIC.

Estudios Geográficos

Tomo LXI, 2000, n. ${ }^{\circ} 240$, julio-septiembre 
población de los países del Sur. No obstante lo cual, el desequilibrio económico continúa, exagerándose, si cabe.

En los apartados segundo y tercero se aborda la caracterización de la inmigración española en los años 90, compuesta progresivamente por más y más africanos, latinoamericanos y asiáticos. A continuación, nos detenemos a analizar la inmigración subsahariana, comparándola con la magrebí. «La presencia africana en la inmigración española del cambio de siglo» es un estudio de la progresiva africanización de los inmigrantes en España. No es un estudio monográfico de los africanos que están viviendo, o preparándose para vivir, en España.

El apartado cuarto profundiza en el tratamiento legislativo y político de la inmigración española. Finalmente, en las conclusiones, se pasa revista a los aspectos más importantes de nuestro estudio, que apuntan a un asentamiento progresivo de los inmigrantes laborales, que siguen llegando en cantidades más importantes, desde lugares más diversos y remotos (el caso de China es particularmente interesante). Mientras, se va gestando una política inmigratoria española al estilo de la de otros países Schengen.

\section{Inmigrantes africanos en la Europa meridional}

El panorama de la inmigración en Europa durante las dos últimas décadas del siglo $\mathrm{xx}$ ha estado presidida por la incertidumbre y el malestar, tanto de los naturales, como de los inmigrantes, que han calado más hondo en los países de Europa meridional. Estos son los países que han abandonado su condición tradicional de países de emigración, convirtiéndose en países receptores de población extranjera.

Europa recibe importantes flujos de migración procedente de África, debido a la relativa proximidad de ambos dominios geográficos $\mathrm{y}$, también, a las relaciones coloniales que, hasta hace varias décadas, han conectado la casi totalidad de los países africanos con algún país europeo. La componente magrebí de esta corriente migratoria es, con mucho, la más significativa.

La explicación de este fenómeno argumenta que los movimientos de población que estamos considerando se deben, fundamentalmente, a desequilibrios económicos (la Europa rica que atrae a los africanos más desfavorecidos) y demográficos (África expulsa individuos que le «so- 
bran», mientras Europa los acoge, porque los necesita como trabajadores). A pesar de lo cual, la situación correspondiente a los últimos 90 es bastante menos contrastada que la que caracteriza a los últimos 80 , como veremos a continuación, al menos entre las dos riberas del Mediterráneo.

CUADRo I

DESEQUILIBRIOS ECONÓMICOS Y DEMOGRÁFICOS EN TORNO AL MEDITERRÁNEO

\begin{tabular}{|c|c|c|c|c|c|c|c|c|c|}
\hline & $\begin{array}{c}\text { RPC* } \\
1983\end{array}$ & $\begin{array}{l}\text { RPC } \\
1989\end{array}$ & $\begin{array}{l}\text { RPC } \\
1997\end{array}$ & $\begin{array}{c}\text { Pobla- } \\
\text { ción** }^{*} \\
1985\end{array}$ & $\begin{array}{c}\text { Pobla- } \\
\text { ción** } \\
1990\end{array}$ & $\begin{array}{c}\text { Pobla- } \\
\text { ción** } \\
1997\end{array}$ & $\begin{array}{c}\text { Proyec- } \\
\text { ción de } \\
\text { pobla- } \\
\text { ción** } \\
\text { para el } \\
2000 \\
(1985)\end{array}$ & $\begin{array}{c}\text { Proyec- } \\
\text { ción de } \\
\text { pobla- } \\
\text { ción** } \\
\text { para el } \\
2020 \\
1985 \text { ) }\end{array}$ & $\begin{array}{c}\text { Proyec- } \\
\text { ción de } \\
\text { pobla- } \\
\text { ción** } \\
\text { para el } \\
2030 \\
(1997)\end{array}$ \\
\hline Portugal & 2.190 & 4.260 & 10.428 & 10 & 10,5 & 9,8 & 11 & 12 & 10 \\
\hline España & 4.800 & 9.150 & 14.111 & 38 & 39,0 & 39,3 & 42 & 43 & 36 \\
\hline Francia & 10.390 & 17.830 & 26.444 & 55 & 56,5 & 58,6 & 57 & 57 & 61 \\
\hline Italia & 6.350 & 15.150 & 19.121 & 57 & 57,0 & 57,5 & 58 & 55 & 51 \\
\hline Grecia & 3.970 & 5.340 & 8.684 & 10 & 10,0 & 10,5 & 11 & 12 & 10 \\
\hline Marruecos & 750 & 900 & 1.265 & 24 & 25,0 & 26,0 & 37 & 59 & 42 \\
\hline Argelia & 2.400 & 2.170 & 1.531 & 22 & 25,0 & 29,0 & 35 & 53 & 51 \\
\hline Túnez & 1.290 & 1.260 & 2.110 & 7 & 8,0 & 9,2 & 10 & 13 & 14 \\
\hline Libia & 7.500 & 5.400 & 5.498 & 4 & 4,5 & 5,7 & 7 & 11 & 9 \\
\hline Egipto & 700 & 630 & 973 & 48 & 53,0 & 62,0 & 67 & 94 & 93 \\
\hline Turquía & 1.230 & 1.360 & 2.814 & 52 & 58,5 & 63,7 & 71 & 97 & 90 \\
\hline
\end{tabular}

La lectura de las columnas 1, 2, 4, 5, 7 y 8 de la cuadro I, justifica una preocupación por el contraste del futuro demográfico y económico entre las dos riberas del Mediterráneo: la N-NO por un lado, y la S-SE, por otro.

Las naciones del N-NO del Mediterráneo experimentaban en la década de los ochenta un crecimiento demográfico amortiguado y una ex- 
pansión económica sobresaliente que coincidía, en líneas generales, con su entrada en el Mercado Común (Comunidad Europea, o, posteriormente, Unión Europea). Las naciones de la ribera sur del Mediterráneo, por el contrario, experimentaban un crecimiento económico muy lento, solapado con un desarrollo demográfico más que notable. Así las cosas, en ausencia de políticas migratorias seriamente disuasorias, se preveía la continuación de los flujos de población sur-norte.

Para comprobar si estas tendencias demográficas y económicas se han mantenido, recogemos nuevos datos (columnas tercera, sexta y novena, en negritas) de renta per cápita y población en 1997 y presentamos una proyección de esta última hasta el año 2030. Los datos más recientes proceden del Anuario Demográfico de las Naciones Unidas, lo que garantiza su comparabilidad con los datos del Population Reference Bureau.

En todos los países europeos del Mediterráneo la renta per cápita creció en el periodo 1983-1989. De 1989 a 1997 se ha mantenido en todos ellos la tendencia al alza, aunque en Francia se haya reducido ligeramente la tasa de crecimiento económico. Los datos correspondientes a la ribera S-SE del Mediterráneo, por su parte, confirman, a grandes rasgos, la tendencia observada durante los años 1983-1989. Los que crecieron discretamente en esos años (Marruecos), lo han seguido haciendo. Los que parecían estancados, han prolongado esa situación (Argelia y Libia), o la han mejorado levemente (Túnez). Egipto mantiene sus reducidos valores de renta per cápita, mientras no deja de crecer demográficamente. Turquía, por su parte, apunta la evolución económica más favorable de todo este grupo.

Comparemos la sexta columna, de tamaños de población, que se publica en el Anuario Demográfico de las Naciones Unidas, con las columnas que registran los valores de la población en 1990, y la población proyectada en cada uno de los países considerados para el año 2000. Resulta obvio que las tasas de crecimiento han disminuido más de lo previsible, independientemente de que se trate de países del Norte o del Sur. Las poblaciones de Portugal y España en 1997 son claramente inferiores a las proyectadas para el año 2000. Las poblaciones de Grecia e Italia son prácticamente las mismas que las proyectadas. Francia, en cambio, ha crecido a un ritmo claramente mayor que el proyectado. Por otro lado, todos los países del Sur del Mediterráneo han crecido bastante menos de lo previsto. Los casos más notables son los de Libia y, sobre todo, los de 
Marruecos y Argelia. Turquía y Egipto han crecido proporcionalmente más que los países ya mencionados, pero muy por debajo de los valores anticipados.

Si prestamos atención a las proyecciones para el 2020 (confeccionada en 1985) y para el 2030 (confeccionada en 1997), vemos que, salvo Francia y Túnez, la segunda previsión es mucho menos abultada que la primera, lo que indica que se ha producido un cambio de dinámica demográfica en los países ribereños del Mediterráneo durante los últimos quince años: Ha cambiado la tasa de crecimiento demográfico en toda la región, pero sobre todo en el sur. La situación que refleja esta cuadro resulta tranquilizadora. Nos aleja del escenario catastrofista en el que Europa resultaba anegada por la llegada masiva y descontrolada de riadas de norteafricanos y subsaharianos.

La inmigración española en los noventa: naturaleza de los flujos y distribución geográfica de los inmigrantes

En el marco de los flujos migratorios que tienen lugar entre Africa y Europa, vamos a analizar la situación de la inmigración en nuestro país durante los noventa, prestando especial atención a los flujos que se originan en el continente africano (cuadro II). En España, entre 1991 y 1998 el número de inmigrantes regulares crece, aproximadamente, en 300.000 personas (un incremento del $45 \%$ ).

En la distribución por continentes de origen de los extranjeros que residen legalmente en nuestro país se produce un cambio importante. Desde 1991 se aprecia una considerable reducción de los inmigrantes procedentes de Europa, un ligero aumento de los latinoamericanos y un crecimiento espectacular de la inmigración africana. Debemos recordar que Marruecos se consolida durante estos años como la principal cuenca de los flujos migratorios que se dirigen hacia nuestro país. Por otra parte, la inmigración española en los últimos años ha tendido a «normalizarse», adquiriendo las características de una inmigración predominantemente laboral, como la que se aprecia en otros países de nuestro entorno.

En la legislación española actual, la concesión de un permiso de residencia está condicionado, en la mayoría de los casos, a la obtención de un permiso de trabajo. En el momento presente, la inmigración española 
JUAN A. CEBRIÁN, MARÍA ISABEL BODEGA Y ANA M. LÓPEZ-SALA

CUADRO II

RESIDENTES EXTRANJEROS EN ESPAÑA, POR CONTINENTE DE ORIGEN

\begin{tabular}{|c|c|c|c|c|c|c|}
\hline Continente & Año 1990 & $\%$ & Año 1995 & $\%$ & Año 1998 & $\%$ \\
\hline Europa & 139.713 & 50,2 & 255.702 & 51,2 & 330.528 & 45,9 \\
\hline Asia & 24.718 & 8,2 & 38.352 & 7,7 & 60.714 & 8,4 \\
\hline Africa & 48.742 & 17,7 & 95.718 & 19,2 & 179.487 & 24,94 \\
\hline N y C América & 23.092 & 8,4 & 43.985 & 8,8 & 17.272 & 2,4 \\
\hline S América & 41.186 & 14,9 & 64.947 & 13,0 & 129.928 & 18,0 \\
\hline Oceanía & 599 & 0,3 & 733 & 0,1 & 1.023 & 0,1 \\
\hline $\begin{array}{l}\text { Expatriados } \\
\text { con, o sin, na- } \\
\text { cionalidad }\end{array}$ & 745 & 0,3 & 335 & 0,0 & 695 & 0,0 \\
\hline Total & 278.795 & 100,0 & 499.772 & 100,0 & 719.647 & 100,0 \\
\hline
\end{tabular}

Fuente: Anuario de Migraciones, 1993, 1996.

Anuario Estadístico de Extranjería, 1998. Elaboración propia.

es, predominantemente, laboral. Por ello, las cifras de empleo extranjero son un buen indicador de los flujos inmigratorios españoles. La diferencia entre el número de residentes y el de permisos de trabajo concedidos, refleja la importancia de los tres colectivos que están al margen del mundo laboral: jubilados extranjeros, dependientes de los trabajadores extranjeros y estudiantes extranjeros.

Si se comparan los valores en las cuadros II y III, resulta manifiesto que, en 1991, un porcentaje importante de la inmigración europea era población no activa y, por lo tanto, no sometida al requisito del permiso de trabajo. A partir de 1992, los europeos comunitarios no necesitan permiso de trabajo para extranjeros en ninguno de los países miembros de la Unión Europea. De ahí que en la cuadro III, en la columna correspondiente a 1991, aparezcan 56.558 europeos con permiso de trabajo, que, en 1995, se reducen a 7.057. Es necesario corregir los datos de trabajadores europeos en España a partir del 92; aún así, la inmigración europea se consolida como una inmigración de jubilados en busca de condiciones de vida más confortables. 
CUAdro III

EXTRANJEROS CON PERMISO DE TRABAJO EN VIGOR, POR CONTINENTE DE ORIGEN

\begin{tabular}{lrrrrrr}
\hline Continente & Año 1991 & \multicolumn{1}{c}{$\%$} & Año 1995 & \% & Año 1998 & \multicolumn{1}{c}{$\%$} \\
\hline Europa & 56.558 & 33,3 & 7.057 & 5,0 & 9.785 & 5,4 \\
Asia & 19.083 & 11,1 & 20.529 & 14,5 & 26.202 & 14,6 \\
Africa & 51.155 & 29,9 & 64.778 & 46,5 & 86.876 & 48,6 \\
N América & 6.056 & 3,5 & 4.591 & 1,7 & 2.464 & 1,6 \\
$\begin{array}{l}\text { C y S América } \\
\text { Oceanía }\end{array}$ & 37.708 & 22,0 & 43.521 & 31,0 & 53.082 & 29,6 \\
$\begin{array}{l}\text { Expatriados } \\
\text { con, o sin, na- }\end{array}$ & 251 & 0,1 & 120 & 0,15 & 137 & 0,1 \\
cionalidad & & & & & & \\
\multicolumn{1}{l}{ Total } & 222 & 0,1 & 132 & 0,15 & 201 & 0,1 \\
& 171.003 & 100,0 & 138.659 & 100,0 & 178.747 & 100,0
\end{tabular}

Fuente: Anuario de Migraciones, 1993, 1996, 1998.

Anuario Estadístico de Extranjería, 1998. Elaboración propia.

La inmigración africana y latinoamericana tienen, por otra parte, una orientación claramente laboral en el periodo considerado. La inmigración africana se destaca como inmigración laboral en crecimiento. Por su parte, aunque la inmigración latinoamericana aumenta, los permisos de trabajo para latinoamericanos no crecen al mismo ritmo. Esto es debido bien a la adquisición de la nacionalidad española por parte de muchos latinoamericanos, o bien a su matrimonio con españoles $u$ otros latinoamericanos previamente nacionalizados.

Asia inicia una tímida subida que, de confirmarse, la acercaría progresivamente a América del Sur, como continente de origen de trabajadores extranjeros en España. El flujo asiático que, inicialmente, estuvo compuesto por mujeres filipinas que venían a trabajar en el servicio doméstico, se ha diversificado recientemente. España se ha convertido en un país atractivo para la comunidad china, que se ha multiplicado por cinco desde principios de los noventa.

Dentro de este marco, los norteafricanos - los magrebies y, más específicamente, los marroquíes - continúan llegando a España, para trabajar, cada vez en mayor número. De 1990 a 1995 han triplicado su im- 
JUAN A. CEBRIÁN, MARÍA ISABEL BODEGA Y ANA M. LÓPEZ-SALA

CuAdro IV

NACIONALIZACIÓN DE EXTRANJEROS EN ESPAÑA, POR CONTINENTE DE ORIGEN

\begin{tabular}{|c|c|c|c|c|c|c|}
\hline Continente & Año 1991 & $\%$ & Año 1995 & $\%$ & Año 1998 & $\%$ \\
\hline Europa & 609 & 16,0 & 713 & 10,5 & 1.329 & 10,1 \\
\hline Asia & 511 & 13,6 & 778 & 11,5 & 1.400 & 10,7 \\
\hline Africa & $* 577$ & 15,3 & $* * 1.060$ & 15.6 & 2.150 & 16,4 \\
\hline N y C América & 430 & 11,4 & 950 & 14,0 & 106 & 0,9 \\
\hline S América & 1.587 & 42,0 & 3.215 & 47,5 & 8.143 & 61,9 \\
\hline Oceanía & 4 & 0,1 & 3 & 0,04 & 5 & 0,0 \\
\hline Otros & 34 & 1,0 & 37 & 0,5 & 40 & 0,0 \\
\hline Total & 3.752 & 100.0 & 6.756 & 100.0 & 13.177 & 100,0 \\
\hline
\end{tabular}

* 427 de Marruecos

** 785 de Marruecos

Fuente: Anuario de Migraciones, 1996

Anuario Estadístico de Extranjería, 1998. Elaboración propia.

portancia, alcanzando en esa fecha, prácticamente, el umbral de los 100.000 individuos, en situación legal, procedentes de Marruecos.

La consolidación y el aumento de los flujos que se originan en Marruecos, y en algunos países de América Latina, ha tenido como resultado una modificación apreciable de la política española de visados. Nos estamos refiriendo a la exigencia de este requisito a los marroquíes y peruanos (desde 1991) y a los dominicanos (desde 1993). Esta modificación política que puede, aparentemente, resultar poco significativa, ha enturbiado ligeramente las relaciones de nuestro país con las antiguas posesiones de ultramar. Las modificaciones en política de visados se producen con ocasión de la entrada de España en el «espacio Schengen».

Prestemos ahora atención a la cuadro de nacionalización de extranjeros en 1991, en 1995 y en 1998 (cuadro IV), para considerar otros rasgos de la reciente inmigración española. Nos referimos a la existencia de un segmento de inmigrantes con un alto nivel de arraigo que han decidido adoptar la nacionalidad española. En primer lugar, hay que reconocer el sesgo del proceso de nacionalización a favor de los latinoamericanos, que acaparan el $60 \%$ de las nacionalizaciones. Recorde- 
mos que la ley española de nacionalidad prioriza a este colectivo en lo referente al período de residencia. Frente al régimen general que exige un período continuado de residencia de diez años, los latinoamericanos solamente necesitan dos años, al igual que los naturales de otros países con los que España tuvo fuertes vínculos históricos o coloniales como Portugal, Guinea Ecuatorial, Filipinas y Brasil.

En este aspecto, la política española no difiere de la de los países europeos que cancelaron su imperio colonial al terminar la segunda guerra mundial. Tanto Inglaterra como Francia u Holanda ofrecieron ventajas laborales y de asentamiento a los inmigrantes procedentes de sus antiguas colonias, frente a los procedentes del Mediterráneo, durante los años de la reconstrucción e industrialización centroeuropea. España, ahora, necesitada de trabajadores que ocupen los empleos que los autóctonos descartan, favorece el establecimiento de individuos de semejante pasado cultural (castellano parlantes, al menos), para aminorar, en lo posible, los costos de integración social.

Por otro lado, los datos de la cuadro IV, confirman la hipótesis de que la inmigración laboral actual a España no es temporal. La prueba de ello es que, independientemente de los inmigrantes latinoamericanos, en 1995, se nacionalizaron 1.060 africanos (785 de ellos, marroquíes) y 778 asiáticos, lo que supone más del $25 \%$ del total de nacionalizados. Los datos de 1998 lo corroboran.

La inmigración española muestra una pauta de fuerte concentración geográfica (cuadro V). Las seis regiones con mayor número de inmigrantes son: Cataluña, Madrid, Andalucía, Valencia, Canarias y Baleares. Esta última duplica el número absoluto de inmigrantes residentes de la región autónoma de Castilla - León, que ocupa el séptimo lugar en la lista.

Si prestamos ahora atención a la localización de estas seis Comunidades, vemos que se consolida el patrón de distribución espacial de la inmigración reciente a España. Los residentes extranjeros se concentran, principalmente, en el litoral mediterráneo, desde la frontera con Francia hasta el estrecho de Gibraltar y, en segundo término, en la Comunidad Autónoma de Madrid, que ocupa una posición central en el territorio de la nación. Se han mantenido las causas que justifican este patrón espacial desde la publicación de nuestro anterior artículo (Bodega, I, Cebrián, JA y otros, 1993). Los inmigrantes prefieren instalarse en las grandes ciudades, por cuanto éstas generan puestos de trabajo muy 
CUADRo V

RESIDENTES EXTRANJEROS EN ESPAÑA, POR COMUNIDAD AUTÓNOMA DE DESTINO

\begin{tabular}{lrrrrrr}
\hline Comunidad & Año 1990 & \multicolumn{1}{c}{ \% } & Año 1995 & \% & Año 1998 & \% \\
\hline Andalucía & 37.663 & 12,9 & 67.127 & 13,4 & 95.970 & 13,3 \\
Aragón & 3.635 & 1,3 & 6.877 & 1,4 & 11.877 & 1,6 \\
Asturias & 4.463 & 1,6 & 6.562 & 1,3 & 8.682 & 1,2 \\
Baleares & 15.948 & 5,4 & 28.111 & 5,6 & 40.399 & 5,6 \\
Canarias & 26.987 & 9,3 & 53.188 & 10,6 & 68.848 & 9,5 \\
Cantabria & 13.052 & 4,6 & 2.864 & 0,6 & 3.910 & 0,5 \\
Castilla - León & 8.153 & 2,9 & 14.628 & 3,0 & 20.113 & 2,8 \\
Castilla-La Man. & 2.304 & 0,9 & 6.516 & 1,3 & 11.374 & 1,5 \\
Cataluña & 47.003 & 16,1 & 106.809 & 21,4 & 148.803 & 20,6 \\
Valencia & 36.686 & 12,6 & 57.790 & 11,5 & 69.972 & 9,7 \\
Extremadura & 2.374 & 0,8 & 5.060 & 1,0 & 9.063 & 1,2 \\
Galicia & 9.739 & 3,4 & 16.833 & 3,3 & 21.140 & 2,9 \\
Madrid & 62.742 & 21,6 & 93.031 & 18,6 & 148.070 & 20,6 \\
Murcia & 4.859 & 1,6 & 7.390 & 1,5 & 15.731 & 2,2 \\
Navarra & 1.983 & 0,6 & 4.202 & 0,8 & 6.385 & 0,9 \\
País Vasco & 7.276 & 2,5 & 13.569 & 2,7 & 16.995 & 2,3 \\
Rioja & 761 & 0,2 & 1.659 & 0,3 & 3.253 & 0,4 \\
Ceuta y Melilla & 1.347 & 0,4 & 1.859 & 0,4 & 2.250 & 0,3 \\
No consta & 3.882 & 1,3 & 5.698 & 1,1 & 16.812 & 2,3 \\
\multicolumn{1}{c}{ Total } & & & & & & \\
& 290.857 & 100,0 & 499.773 & 100,0 & 719.647 & 100,0
\end{tabular}

Fuente: Anuario de Migraciones, 1993, 1996.

Anuario Estadístico de Extranjería, 1998.Elaboración propia.

diversos que la población natural del país no está dispuesta a ocupar (el caso más patente es el servicio doméstico). Además, en la ciudad es fácil ocultar determinados negocios ilegales, donde se contrata a inmigrantes «sin papeles» por salarios mínimos.

Por otra parte, los inmigrantes se dirigen hacia las zonas en las que las actividades agrícolas demandan abundante mano de obra temporera, lo que coincide, prácticamente, con la región costera mediterránea, con máximos en Almería (Campo de Dalías, El Ejido y Roquetas: 4.855 en 1996), Barcelona (El Maresme: 3.056 en 1996) y Murcia (6.637 
en 1996). Esta última Comunidad, aunque no aparece entre las seis grandes, es la que más trabajadores agrícolas extranjeros atrae. En estas zonas, no es difícil que la agricultura sea también caldo de cultivo para la contratación ilegal.

Además, el sector turístico, tan importante en España, ejerce una atracción adicional de trabajadores nacionales, y extranjeros, a tiempo parcial, ya sea en los servicios, la venta ambulante o la construcción, en la costa mediterránea.

Desde la primera inspección del cuadro VI se descubren dos tipos de regiones inmigratorias: a) regiones donde predominan los centroeuropeos (migración de jubilados), y b) regiones en las que destacan los inmigrantes de África y Latinoamérica (migración laboral). Las regiones de Andalucía, Baleares, Canarias, Cataluña, Comunidad Valenciana y Madrid absorben el contingente de extranjeros más importante (ver también cuadro V). Por otro lado, la distribución de los inmigrantes por procedencia - en estas seis regiones-, resulta bastante equilibrada.

Si prestamos ahora atención a los países de origen de los inmigrantes en España, en 1998, comprobamos la importancia de la componente europea en el total de residentes extranjeros en nuestro país. Al mismo tiempo, este tipo de estadística oficial refleja la importancia de los residentes marroquíes. Los catorce países de origen de los que consta oficialmente un mayor número de inmigrantes en España son: Marruecos (140.896, ver figura 1), Reino Unido (74.419), Alemania (58.089), Portugal (42.310), Francia (39.504), Italia (26.514), Perú (24.879), República Dominicana (24.256), China (20.690), Argentina (17.007), Holanda (16.144), USA (15.526), Filipinas (13.553) y Cuba (13.214).

Si lo que nos interesa es qué tipo de inmigrantes están más o menos representados y en qué regiones, vemos claramente que los europeos se localizan, preferentemente, en la costa mediterránea y en las Islas Baleares y Canarias. La presencia permanente de europeos en esas zonas se explica por sus recursos turístico residenciales. Portugal es un caso aparte que por su proximidad a España y la pertenencia de ambos a la UE, envía tipos muy distintos de inmigrantes. En función de sus objetivos, los portugueses se establecen sobre todo en regiones próximas a Portugal, aunque también se distribuyen por las restantes regiones españolas, incluso por aquéllas que no reciben prácticamente inmigrantes de otros países. 


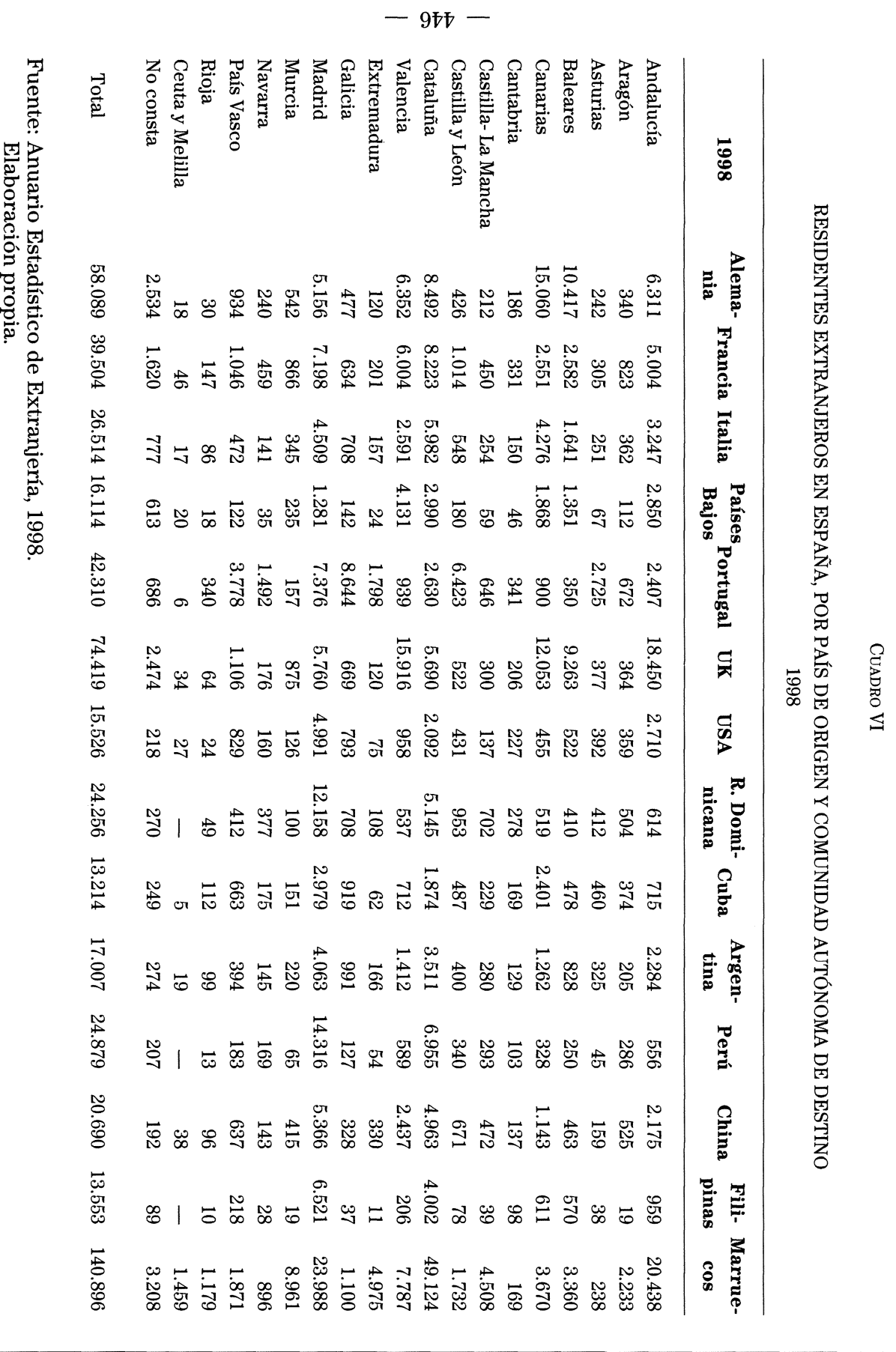

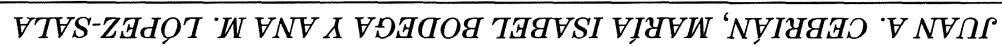




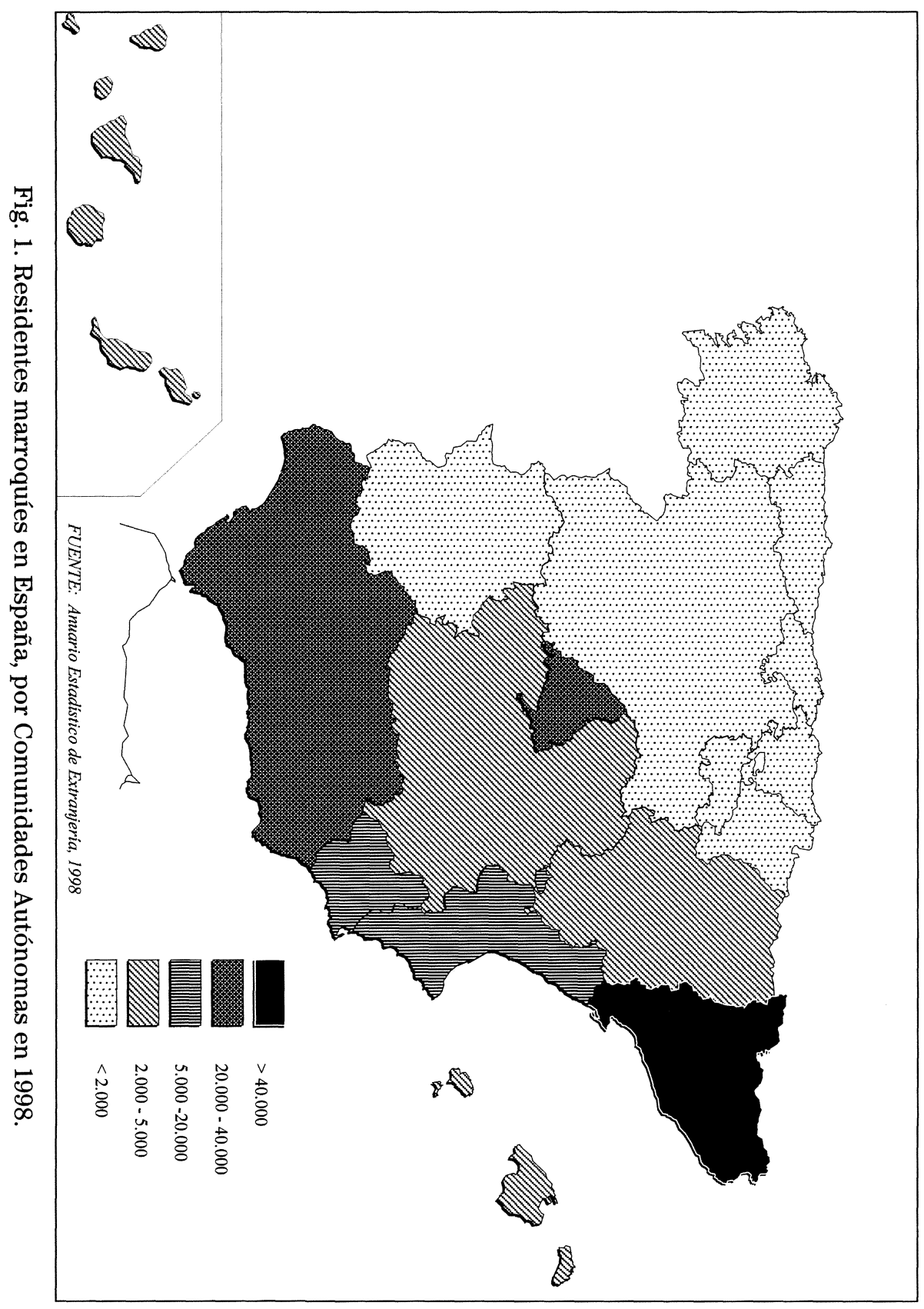

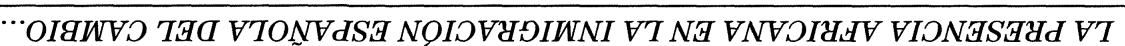


Comprobemos finalmente que los inmigrantes no europeos se distribuyen entre las regiones donde existe una demanda de trabajo importante (también la producida por actividades turísticas). Así, resulta que son atraídos, sobre todo, por los dos mercados de trabajo más importantes: Cataluña y la Comunidad Autónoma de Madrid.

\section{Los inmigrantes subsaharianos}

La inmigración africana española es una emigración marroquí: 140.896 personas. Esta población supone el 78\% de todos los residentes extranjeros africanos en nuestro país. Argelia, en segundo lugar, pero a una distancia notable de Marruecos — son sólo 7.043 los argelinos-, refuerza el carácter magrebí y norteafricano de esta corriente migratoria. Frente a ellos, sólo los gambianos y los senegaleses, que suman 13.626 individuos, aproximadamente la mitad del total de residentes subsaharianos en España, deben considerarse.

Si introducimos la dimensión temporal, nos encontramos con que tanto África, como los países africanos, en el año 1998, «han enviado más residentes» a España que en el 1997. El porcentaje de variación de los residentes procedentes de Africa ha sido de un 25,68\%; 26,43\% el de los norteafricanos - $26,82 \%$ el de los marroquíes y $21,41 \%$ el de los argelinos-; $22,06 \%$ el de los restantes africanos - $19,27 \%$ el de los gambianos y 24,94\% el de los senegaleses (Anuario Estadístico de Extranjería, 1998). Procediendo de la misma etnia, senegaleses y gambianos adoptan una distribución espacial diferente, como resultado de su principal actividad económica en España. Los senegaleses, comerciantes, se distribuyen casi uniformemente por toda España. Los gambianos, trabajadores agrícolas, aparecen muy concentrados en Cataluña, en Barcelona principalmente.

Geográficamente hablando, Senegal y Gambia constituyen el norte del sur del Sahara. Una vez más, la proximidad entre los orígenes y destinos repercute sobre la intensidad de las corrientes migratorias. Hay también razones de tipo histórico y cultural, por supuesto: los Senegaleses han sido siempre los viajeros, los comerciantes del mundo subsahariano.

Prestemos atención ahora al cuadro VII para apreciar el aumento de los inmigrantes «senegambianos» ${ }^{1}$ (el grupo de inmigrantes subsaha-

\footnotetext{
${ }^{1}$ Los senegaleses y gambianos, aunque políticamente distintos por el trazado de las fronteras poscoloniales, pertenecen al mismo grupo etnocultural.
} 
CUADRO VII

RESIDENTES GAMBIANOS, SENEGALESES Y MARROQUÍES EN ESPAÑA 1990-1998

\begin{tabular}{lrrrrrrrrr}
\hline & $\mathbf{1 9 9 0}$ & $\mathbf{1 9 9 1}$ & $\mathbf{1 9 9 2}$ & $\mathbf{1 9 9 3}$ & $\mathbf{1 9 9 4}$ & $\mathbf{1 9 9 5}$ & $\mathbf{1 9 9 6}$ & $\mathbf{1 9 9 7}$ & $\mathbf{1 9 9 8}$ \\
\hline Gambia & 1.938 & 1.938 & 2.952 & 3.210 & 3.441 & 4.219 & 4.402 & 5.843 & 6.969 \\
$\begin{array}{l}\text { Senegal } \\
\text { Senegal }\end{array}$ & 1.752 & 1.895 & 3.190 & 3.203 & 3.389 & 3.855 & 3.575 & 5.328 & 6.657 \\
+ Gambia & 3.690 & 3.833 & 6.142 & 6.413 & 6830 & 8075 & 7.977 & 11.171 & 13.626 \\
\%(Sengam, & & & & & & & & & \\
Marruecos) & $22 \%$ & $7 \%$ & $11 \%$ & $10 \%$ & $10 \%$ & $10 \%$ & $10 \%$ & $10 \%$ & $9 \%$ \\
Marruecos & 16.665 & 49.513 & 54.105 & 61.303 & 63.939 & 74.886 & 77.189 & 111.110 & 140.896
\end{tabular}

Fuente: Anuario de Migraciones, 1997.

Anuario Estadístico de Extranjería, 1998.

Elaboración propia.

rianos más numeroso), que se han cuadruplicado en los años 1990-1998. Aún así, lo primero que hay que subrayar en el cuadro VII es la enorme diferencia (un orden de magnitud) que existe entre el número de inmigrantes marroquíes y la suma de inmigrantes senegaleses y gambianos. En el cuadro VII se detecta un salto brusco del número de inmigrantes marroquíes legales entre los años 1990 (16.665) y 1991 (49.513), que se corresponde con un proceso importante de regularización de inmigrantes. Muchos de los marroquíes del 91 estaban ya aquí, pero en situación irregular (Bodega, I, Cebrián, J. A., y otros, 1993). En el cuadro VII se puede comprobar que, a partir de esa regularización, los «senegambianos» no pasan nunca de ser la décima parte de los marroquíes en España, que se han multiplicado por nueve en la década de los noventa.

En el Anuario Estadístico de Extranjería del 98 aparecen los siguientes datos sobre residentes extranjeros. Nigerianos: 1.464, en España; angoleños: 700, en España; caboverdianos $^{2}$ : 2.691, en España.

2 La inmigración caboverdiana presenta características singulares. En primer lugar se aprecia un equilibrio entre los sexos de los inmigrantes, que se debe a la frecuencia de los matrimonios de inmigrantes. El hombre trabaja como peón (en las minas, por ejemplo, en León), y la mujer como empleada de hogar. La mayor parte de ellos llegan a España a través de Portugal (antigua metrópoli), donde constituyen el colectivo más importante de inmigrantes africanos. 


\section{CUADRo VIII}

DISTRIBUCIÓN POR COMUNIDADES AUTÓNOMAS DE LOS RESIDENTES EXTRANJEROS DE LOS DOS PAÍSES NORTEAFRICANOS Y LOS DOS SUBSAHARIANOS MÁS REPRESENTADOS EN ESPAÑA (1998)

\begin{tabular}{lrrrr}
\hline \multicolumn{1}{c}{ 1998 } & Senegal & Gambia & Argelia & Marruecos \\
\hline Andalucía & 1.464 & 171 & 844 & 20.438 \\
Aragón & 577 & 513 & 657 & 2.233 \\
Asturias & 113 & 2 & 36 & 238 \\
Baleares & 277 & 21 & 235 & 3.360 \\
Canarias & 426 & 49 & 90 & 3.670 \\
Cantabria & 74 & 2 & 24 & 169 \\
Castilla - La Mancha & 36 & 15 & 149 & 4.508 \\
Castilla y León & 199 & 56 & 80 & 1.732 \\
Cataluña & 1.588 & 5.675 & 1.152 & 49.124 \\
Valencia & 797 & 36 & 1.694 & 7.787 \\
Extremadura & 76 & 9 & 33 & 4.975 \\
Galicia & 333 & 0 & 54 & 1.100 \\
Madrid & 323 & 28 & 592 & 23.988 \\
Murcia & 57 & 48 & 512 & 8.961 \\
Navarra & 135 & 0 & 326 & 896 \\
País Vasco & 111 & 3 & 138 & 1.871 \\
Rioja & 4 & 2 & 203 & 1.179 \\
Ceuta y Melilla & 14 & 7 & 140 & 1.459 \\
No consta & 50 & 332 & 84 & 3.208 \\
$\quad$ Total & & & & \\
& 6.657 & 6.969 & 7.043 & 140.896
\end{tabular}

Fuente: Anuario Estadístico de Extranjería, 1998. Elaboración propia.

Mientras tanto, hay 6.657 senegaleses y 6.969 gambianos, 13.626 senegambianos. Por ello, no les hemos dedicado gran espacio en este trabajo.

La década de los ochenta presenció la llegada irregular de subsaharianos a España, aprovechando la permeabilidad de las fronteras españolas en aquellos años. La década de los noventa, en cambio, a partir de la regularización del 91, ha asistido al reconocimiento legal de su asentamiento - y el de los que han llegado siguiendo su pista - y a la custodia más eficaz de las puertas de entrada a nuestro país (figura 2). En la regularización del 91, Senegal, con 2.113 regularizados, fue primero en- 


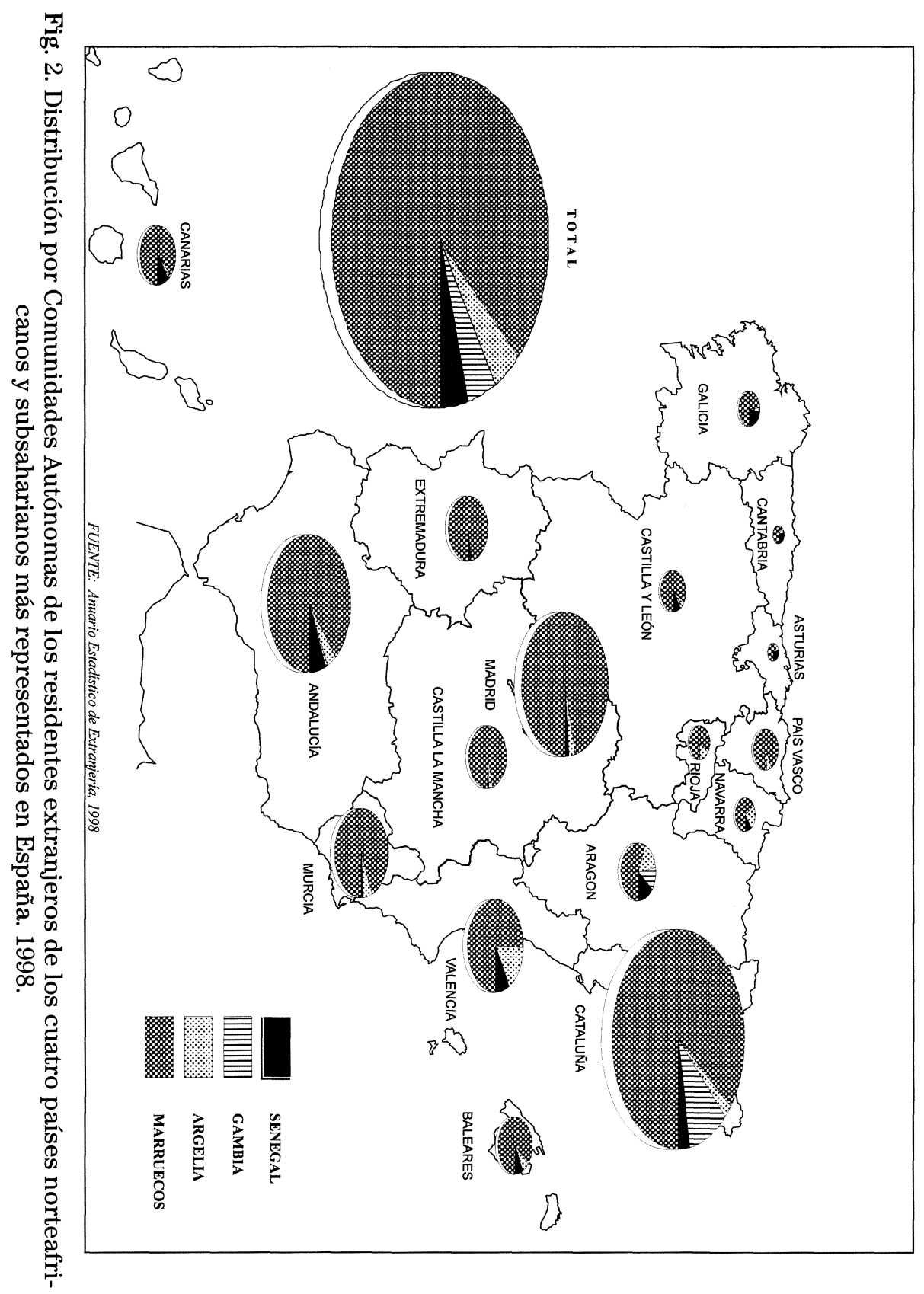

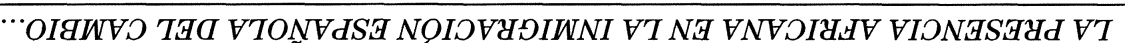


tre todos los países subsaharianos. Gambia, con 2.040 regularizados, el segundo.

En la actualidad, a pesar de los nuevos controles fronterizos y de la mayor agilidad de los trámites administrativos, los números de residentes subsaharianos que se publican siguen quedándose cortos, debido a la tasa de irregularidad de este colectivo, superior a la de los norteafricanos. Los inmigrantes subsaharianos son varones jóvenes, o muy jóvenes, en su gran mayoría (ver figuras $3 \mathrm{a}$ y $3 \mathrm{~b}$ ). Salvo en el caso de las caboverdianas, las mujeres que Africa envía a España tienen como motivación, casi exclusiva, la reagrupación familiar (Vicente, J., 1993).

En los últimos años, los senegaleses - y otros inmigrantes subsaharianos, y algunos norteafricanos- han barrido a los gitanos en la venta ambulante. Lo que también puede expresarse de otras maneras. Por ejemplo, que los gitanos afincados en España han mejorado su posición en la estructura ocupacional desde la llegada de nuevos inmigrantes que han ocupado alguno de los nichos laborales explotados anteriormente por ellos; los senegaleses han demostrado una capacidad de trabajo impresionante y una movilidad geográfica más que notable. El resultado ha sido el establecimiento de redes comerciales muy sólidas.

La ciudad de Granada es un punto importante de asentamiento y residencia de la comunidad senegalesa. No obstante lo cual, está bastante repartidos por el territorio español. Los senegaleses proceden de la zona centro-este de su país, que es también la zona más urbanizada. De la zona rural no viene «nadie» a España. Además, una parte significativa de este colectivo en España procede de familias de tradición comercial (Suárez, 1995).

Pocos senegaleses pueden mandar dinero a casa. A la mayoría, «no les salen las cuentas»: vivienda, alimentación, transporte, impuestos profesionales, seguridad social, etc. Suelen establecerse en pensiones, donde se hacinan. Los cascos antiguos de las ciudades españolas disponen de un buen número de pensiones. También abundan en el casco histórico los «mercadillos», los enclaves turísticos, etc., donde venden «sus baratijas». Y los mayoristas, cuando pueden, se instalan también en sectores céntricos. El circuito funciona: mayoristas, senegaleses, venta al por menor en la calle: ropa, relojes, etc. Estas transacciones son ilegales en la mayoría de los casos, como lo son los vendedores. Gran parte de la mercancía viene de Marruecos, sobre todo cuando se trata de objetos de cuero. Pero ya han empezado a llegar objetos vía Nueva 


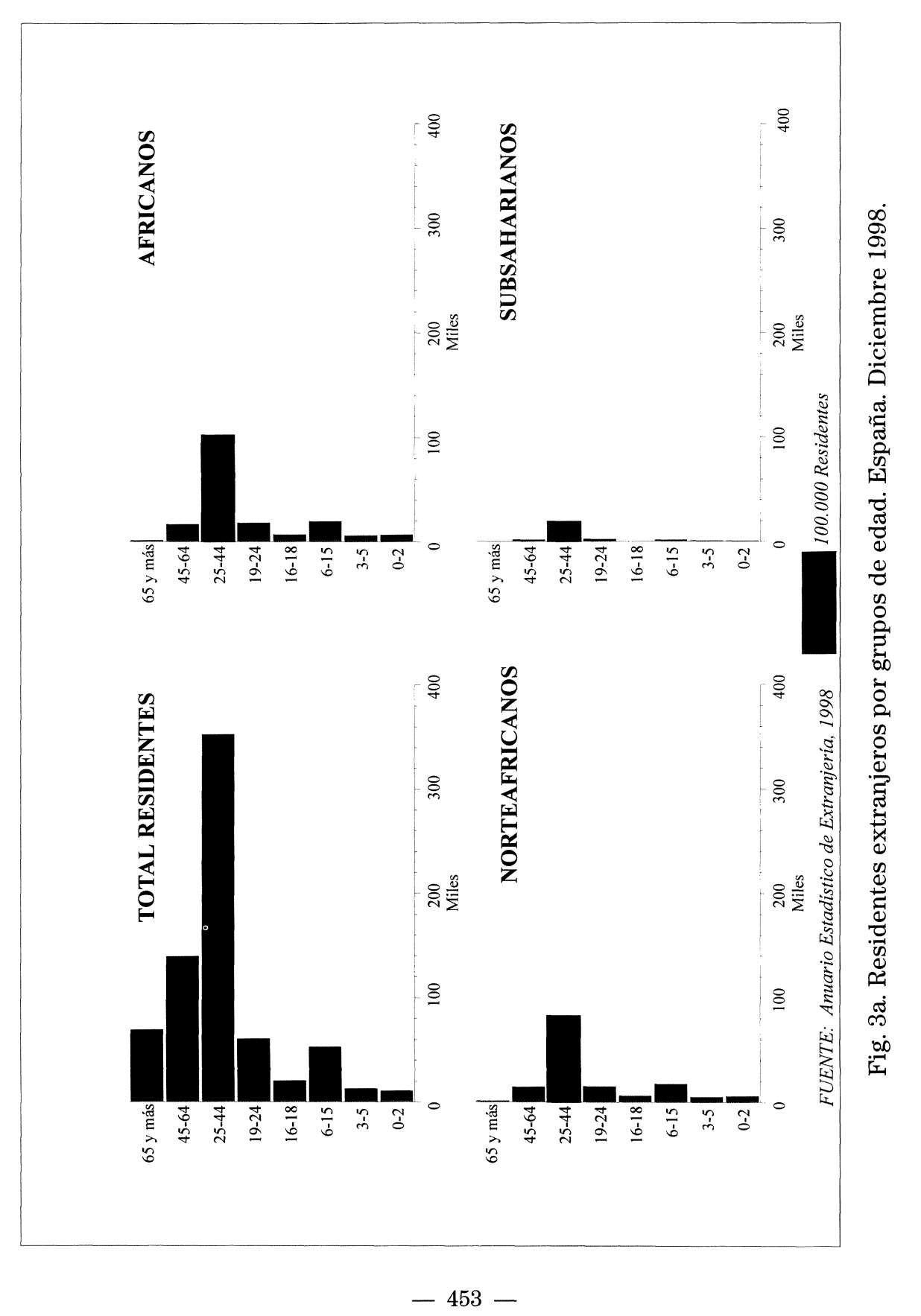




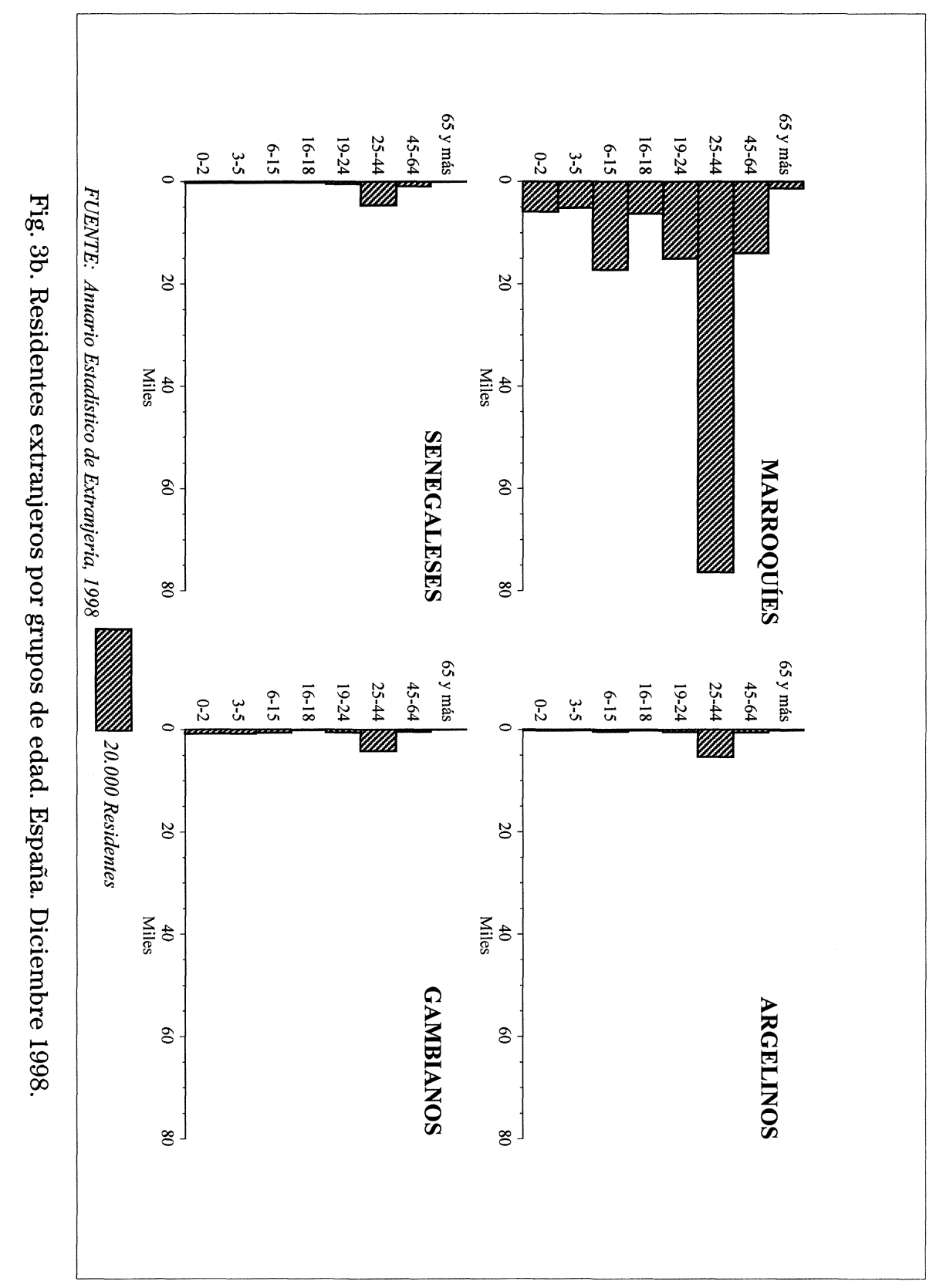

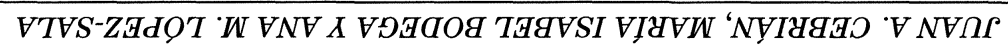


CUADRo IX

RESIDENTES EXTRANJEROS, 1998

\begin{tabular}{lrrrrc}
\hline Nacionalidad & Mujeres & Varones & No consta & Total & $\begin{array}{c}\text { Sex ratio } \\
\text { (M/V) }\end{array}$ \\
\hline Total & 334.612 & 359.899 & 25.136 & 719.647 & 0.92 \\
Africa & 55.526 & 116.964 & 6.997 & 179.487 & 0.47 \\
N Africa & 46.694 & 97.315 & 5.566 & 149.575 & 0.47 \\
Marruecos & 44.912 & 90.821 & 5.163 & 140.896 & 0.49 \\
Argelia & 1.351 & 5.352 & 340 & 7.043 & 0.25 \\
R Africa & 8.832 & 19.649 & 1.431 & 29.912 & 0.44 \\
Senegal & 1.152 & 5.308 & 197 & 6.657 & 0.21 \\
Gambia & 1.891 & 4.582 & 496 & 6.969 & 0.41
\end{tabular}

Fuente: Anuario Estadístico de Extranjería, 1998. Elaboración propia.

York o Italia, por ejemplo, demostrando la importancia de las redes comerciales senegalesas.

Los índices de feminidad («sex ratio», cuadro IX) de diferentes comunidades de inmigrantes africanos, la publicación reciente de números de peticiones de permisos de residencia por reagrupación familiar y de datos de escolaridad de hijos de inmigrantes, nos permiten calibrar el grado de madurez alcanzada por el fenómeno inmigratorio procedente del África subsahariana.

En 1997 tienen lugar en España 23.972 peticiones de permisos de residencia por reagrupación familiar: un $4 \%$ del total de residentes extranjeros en nuestro país, 609.813 , en esas fechas ${ }^{3}$. África es el continente de procedencia del mayor número de peticiones de residencia por reagrupación familiar: 16.140. A su vez, es también el que recibe un mayor número de respuestas negativas: 5.997 (37\%). Dentro de África, Marruecos es el protagonista de este suceso: 14.313 peticiones, 5.295 denegadas (37\%). Como punto de comparación, nos interesa mencionar

\footnotetext{
${ }^{3}$ Hay que ser muy cauto al interpretar los datos de 1997, porque en la tabla de distribución de peticiones por provincias y comunidades autónomas resulta que no hay datos para Madrid (¿No hay datos? ¿Se han perdido?), Baleares, Murcia, Ceuta y Cantabria. Por otra parte, en cambio, extraña la distribución de permisos denegados, que se concentra en casi su totalidad en la provincia de Barcelona (8.863 permisos denegados, de un total nacional de 8.911).
} 
que las peticiones procedentes de Asia han sido 3.750, y las de Latinoamérica 2.585.

Terminamos ya este epígrafe, dedicado a la presentación de las características y condiciones de vida de los inmigrantes subsaharianos, con un comentario de las cifras de escolarización de hijos de inmigrantes más recientes. De esta manera, demostraremos una vez más el carácter definitivo (o a largo plazo) de la inmigración laboral procedente de África. Antes o después, los inmigrantes que se integran reclaman a su familia, forman una nueva - aprovechando alguna visita al país de origen- $o$, también ocurre, se casan con un inmigrante de diferente procedencia, o con un natural del país de destino. No tenemos a mano otro indicador más apropiado que las cifras de escolarización del alumnado extranjero para evaluar la importancia del asentamiento de familias inmigrantes en nuestro país. Así, en el curso 19941995, el Anuario de Migraciones de 1998 publica la existencia de 11.559 alumnos africanos, de los cuales 2.511 son alumnos de preescolar y 7.875, alumnos de primaria. Los marroquíes son ese año 8.576, 1.827 y 6.125 alumnos, respectivamente. En el curso 1995-96 hay ya 14.628 alumnos africanos en España, 3.032 en preescolar y 10.029 en primaria. En ese mismo curso los datos correspondientes a los alumnos marroquíes son 10.881, 2.137 en preescolar, 542 en primaria, 490 en secundaria y 325 en formación profesional. Por otra parte, los alumnos argelinos, senegaleses y gambianos se concentran en la enseñanza preescolar y en primaria.

\section{El tratamiento político de la inmigración en España}

La inmigración entra en la agenda política española debido, fundamentalmente, a los requerimientos que se le hacen a nuestro país desde su incorporación a la Unión Europea. Recordemos que cuando se aprueba la Ley de derechos y libertades de los extranjeros (1985), conocida como Ley de Extranjería, la comunidad inmigrante en España apenas superaba las 250.000 personas. Desde sus comienzos la política española se ha visto profundamente influida por el proceso de integración europea y por nuestra participación en diversos acuerdos supranacionales en materia de seguridad y cooperación, como el Tratado de Schengen o el convenio de Dublín. 
Durante los ochenta la política española es, fundamentalmente, una política de extranjería en la que prima una aproximación policial al fenómeno inmigratorio y en la que se obvian otras cuestiones como la integración o la asignación de derechos a los inmigrantes. En la década de los noventa, en cambio, esta política se diversifica en sus objetivos, convirtiéndose en una política global de inmigración que ha debido ajustarse a las nuevas características que presenta el proceso inmigratorio: la formación de comunidades étnicas, la aparición de una segunda generación o el aceleramiento de la reagrupación familiar. La cuestión inmigratoria se consolida, por tanto, durante esta década como un tema profundamente influyente en los procesos de transformación legislativa y burocrática y con fuerte impacto en la realidad social española.

En los años noventa se aprecia una mejora de los mecanismos políticos y administrativos dirigidos a un control efectivo de los flujos migratorios. Buena muestra de esta situación ha sido el perfeccionamiento de los controles fronterizos, la implantación de una política de visados más severa, la modificación de la normativa en materia de asilo y refugio y el desarrollo de las medidas dirigidas al control interno. No siempre funcionan los mecanismos de control. Por ejemplo, la política de contingentes que se diseña con el objetivo de reclutar y canalizar la mano de obra extranjera hacia los sectores productivos donde se necesita, se ha convertido, en realidad, en un mecanismo anual de regularización de inmigrantes.

El problema de la integración se aborda políticamente desde mediados de los noventa. En 1994 se aprueba el Plan para la Integración Social de los inmigrantes. La redacción de este documento político, en donde se establecen las grandes líneas de actuación en esta materia, se acompaña con la creación del Foro para la Integración Social de los Inmigrantes, un órgano consultivo que se ha mostrado durante estos años profundamente influyente, y con el establecimiento del Observatorio Permanente de la Inmigración, una institución de análisis y diagnóstico de la realidad inmigratoria española. Las acciones integradoras se han extendido fundamentalmente al intercambio cultural, al ámbito escolar, a los servicios sociales y a la asistencia jurídica y laboral de los inmigrantes. Desde 1994 se han diseñado en el ámbito de la escuela distintos instrumentos para asegurar la escolarización de todos los niños inmigrantes, para promover el intercambio cultural y para apoyar a los niños con problemas de aprendizaje: enseñanza compensatoria. Los 
programas de aprendizaje de lengua materna solamente acogen a una pequeña parte de los niños de origen extranjero, en concreto a los marroquíes y portugueses tras los acuerdos adoptados por el gobierno español con ambos países a mediados de esta década.

El desarrollo de estas acciones integradoras se encuentra en contradicción con otros resultados observados en la política española. Las medidas en materia de permisos de trabajo no han asegurado la estabilidad legal o jurídica de los extranjeros lo que ha limitado su acceso a los derechos sociales y económicos y ha restringido las posibilidades de los inmigrantes de reagrupar en nuestro país a sus familiares.

Otra de las transformaciones observadas en los últimos años es el aumento de las instituciones y organizaciones sociales implicadas en la cuestión migratoria en nuestro país. Las administraciones locales y las Comunidades Autónomas aumentan su protagonismo como gestoras de la integración y se multiplican las acciones a favor de los inmigrantes entre las organizaciones no gubernamentales, los sindicatos, la iglesia y las organizaciones de empresarios.

A mediados de 1998 se inician una serie de acciones destinadas a la elaboración de una nueva Ley de Extranjería. Algunas de las modificaciones más importantes que introduce esta ley son el gran peso concedido a la integración en el conjunto de la política española de inmigración, y el aumento de la concesión de derechos a los extranjeros independientemente de su condición jurídica. Esta ley prevé la regularización de los extranjeros que lleven residiendo más de dos años en territorio nacional, la concesión de permisos de trabajo de mayor duración y el reconocimiento del derecho a la reagrupación familiar y del sufragio en las elecciones municipales de los residentes.

\section{Consideraciones finales}

En los años noventa, el incremento de la inmigración africana ha sido notable y se prevé que las cifras sigan aumentando en los próximos años, teniendo en cuenta, por ejemplo, que en el periodo de 1996 a 1998 ha habido un aumento del $81 \%$ en el número de residentes africanos.

Pero no es el reclamo desde España lo que atrae a estos colectivos, sino más bien la realidad socioeconómica de sus respectivos países que les expulsa. En el vecino continente, tener trabajo «es un lujo», pero 
incluso para los que tienen la suerte de percibir un salario, la situación no es mucho mejor, debido a la precariedad de los sueldos, no equiparables, de ningún modo, a los salarios españoles y, menos aún, a los europeos.

En este cambio de siglo, se abre para España un nuevo período cargado de incertidumbres acerca de cómo se gestionará en el futuro la presencia extranjera y, sobre todo, cómo se va a tratar la diversidad cultural ocasionada como consecuencia de los procesos migratorios.

\section{BIBLIOGRAFÍA}

ARANGo, J., 1993. «El Sur en el sistema migratorio europeo. Evolución reciente y perspectivas», Política y Sociedad, $\mathrm{n}^{\circ} 12$. Madrid.

BaGANHA, M., edit., 1997. Immigration in Southern Europe, Portugal, Celta.

Bodega, I., Cebrián, J.A., Franchini, T., Lora-Tamayo, G. y Martín Lou, M. A., 1993. «Migraciones recientes de los países magrebíes a España», Estudios Geográficos, n ${ }^{\circ}$ 210 , páginas. 19-49.

Castles, S. y Miller M., 1995. The Age of Migration, Londres, MacMillan Press.

Cohn-Bendit, D. y Schmid, T., 1995. Ciudadanos de Babel, Madrid, Talasa.

CHECA, F., 1994. Invernaderos e inmigrantes: el problema de la adaptación de un colectivo marginal, Madrid, Dirección General de Migraciones.

— 1995 . «Del riesgo de las pateras a la supervivencia en los invernaderos. Inmigrantes en la provincia de Almería», Revista de Economía y Sociología del Trabajo, núms. 2930 .

- 1998. Africanos en la otra orilla, Barcelona, Icaria.

DoMINGo, C. y GozÁLVEZ, V., 1996. «La inmigración magrebí en España: actualidad y futuro», Boletín de la Asociación de Geógrafos Españoles, $\mathrm{n}^{\circ} 23$, Madrid.

GIMÉNEZ, C., 1992. «Inmigrantes extranjeros: un nuevo componente del mercado de trabajo», Economistas,.$^{\circ} 52$, extra, Madrid.

—, 1992. «Trabajadores extranjeros en la agricultura española: enclaves e implicaciones», Estudios Regionales, n. ${ }^{\circ} 31$, Granada.

GoZÁLVEZ PÉREZ, V., 1995. Inmigrantes marroquíes y senegaleses en la España mediterránea, Valencia, Generalitat Valenciana.

IZQUIERDO ESCRIBANO, A., 1993. «La política de inmigración en España: costes y beneficios de la integración en la Comunidad Europea», Sociedad y Utopía, Revista de Ciencias Sociales, n. $^{\circ} 1$.

IZqUIERDO EsCRIBANo, A., 1996. La inmigración inesperada, Madrid, Trotta.

KING, R., 1993. Mass migration in Europe. The legacy and the future, Londres, Belhaven Press.

LÓPEZ GARCíA, B., 1993. «La inmigración marroquí en España: la relación entre las geografías de origen y destino", Política y Sociedad, n. ${ }^{\circ} 12$, Madrid.

MARTÍNEZ VEIGA, U., 1997. La integración social de los inmigrantes en España, Madrid, Trotta.

PAJARES, M., 1998. La inmigración en España, Barcelona, Icaria.

PuMARES, P., 1996. La integración de los inmigrantes: familias marroquíes en la CAM. Caixa. 
RUIZ DE HUIDOBRo, J., 1998. «Notas sobre el proceso de reforma legislativa en materia de extranjería e inmigración», Migraciones, $\mathrm{n}^{\circ} 4$, Madrid.

SiguAN, M., 1998. La escuela y los inmigrantes. Barcelona. Paidós.

SOPEMI, 1999. Trends in International Migration, París, OCDE.

SuÁREz NAvAz, L., 1995. «Les sénégalais en Andalousie», Mondes en Développement, n. ${ }^{\circ}$ 91, pp. $55-65$.

SÚAREZ NAVAZ, L., 1998. «Los procesos migratorios como procesos sociales. El caso del trasnacionalismo senegalés», OFRIM suplementos, $\mathrm{n}^{\circ} 3$, Madrid.

VARGAS, D. y SANTACRAU, J., coord., 1999. Antropología e Historia contemporánea de la inmigración en España. Alicante, Universidad de Alicante.

VICENTE, J. de, 1993. «Los inmigrantes negroafricanos en la CAM», en Giménez Romero, C. (coordinador), Inmigrantes extranjeros en Madrid, Comunidad de Madrid, II Tomo, pp. 251-336.

RESUMEN: Este artículo trata de explicar las tendencias más recientes dentro de la migración africana hacia España, fenómeno que crece año a año. Estos inmigrantes van a ocupar sectores de trabajo relacionados, sobre todo, con la agricultura, la construcción y el servicio doméstico.

Casi el 95\% de los inmigrantes africanos en España son marroquíes. El resto pertenece a países subsaharianos, como Gambia, Senegal, Cabo Verde, Nigeria, Angola, etc., cuyos colectivos siguen aumentando. Este artículo nos aproxima a las migraciones subsaharianas y a su evolución en un futuro cercano.

Otro punto que se desarrolla es el dedicado a políticas migratorias. La Ley de Extranjería de 1985 fue el primer eslabón de una cadena de estas políticas, que han continuado en los años noventa y que han tenido como resultado la nueva Ley Orgánica sobre Derechos y Libertades de los Extranjeros en España, publicada en enero del año en curso, ley que ha sido elaborada para reconocer los derechos de los inmigrantes en España.

PALABRAS CLAVE: Migraciones internacionales en el siglo xx, Migraciones africanas a Europa meridional, Magrebíes y Subsaharianos en España, Políticas migratorias.

ABSTRACT: This paper looks for an explanation of the most recent trends in African migration to Spain. African migration is a growing phenomenon in the Iberian peninsula, as a labor supply for some economic sectors: commercial agriculture, construction, tourism and domestic services.

Close to $95 \%$ of the African migrants in Spain are Moroccans. Nonetheless, other African countries, like Senegal, Gambia, Cape Verde, Nigeria, Angola, etc. are sending noticeable numbers of people to Spain. This paper approaches the Sub-Saharan migration and its different evolution in the near future.

Several immigration laws have been published since 1985, when the first one 'Ley de Extranjería' was approved. We examine the main changes in Spanish immigration policy as it turns, more and more, a controlling artifact of labor migrants and their integration.

KEY WORDS: International migrations in the 20th century, African migrations to southern Europe, North-African and Sub-Saharan migrants in Spain, Migration policies. 